\title{
Commentary: Patient selection is key to improving postcardiotomy extracorporeal membrane oxygenation outcomes
}

\author{
Weiang Yan, MD, and Michael H. Yamashita, MDCM, MPH, CPH, FRCSC
}

\author{
From the Department of Surgery, Max Rady College of Medicine and Cardiac Sciences Program, St. Boniface \\ Hospital, Winnipeg, Manitoba, Canada. \\ Disclosures: Authors have nothing to disclose with regard to commercial support. \\ Received for publication July 6, 2019; accepted for publication July 8, 2019; available ahead of print Aug 21, \\ 2019. \\ Address for reprints: Michael H. Yamashita, MDCM, MPH, CPH, FRCSC, St Boniface Hospital, Y3519-369 \\ Tache Ave, Winnipeg, Manitoba, Canada R2H 2A6 (E-mail: myamashita@sbgh.mb.ca). \\ J Thorac Cardiovasc Surg 2020;159:1855-6 \\ $0022-5223 / \$ 36.00$ \\ Copyright (c) 2019 by The American Association for Thoracic Surgery \\ https://doi.org/10.1016/j.jtcvs.2019.07.036
}

Postcardiotomy cardiogenic shock (PCS) is associated with significant morbidity and mortality. ${ }^{1}$ For refractory PCS, venoarterial extracorporeal membrane oxygenation (VAECMO) has rapidly become an accepted bridging strategy toward either patient recovery or an alternative therapeutic option. Between 2008 and 2014, the use of VA-ECMO for PCS increased by almost $350 \%$ in US hospitals and is the leading cardiac indication for ECMO among all patients. ${ }^{2}$ Despite this increasing volume, reported outcomes for postcardiotomy VA-ECMO have varied significantly between studies, with survival to discharge ranging from $5.3 \%$ to $67 \% .^{3,4}$ This heterogeneity highlights the importance of patient selection to optimize outcomes and guide appropriate use of limited health care resources.

In this issue of the Journal, Biancari and colleagues ${ }^{5}$ present a large, multicenter, retrospective cohort analysis of outcomes in 781 consecutive patients treated with postcardiotomy VA-ECMO. Overall survival was 35.6\% at hospital discharge and $32.8 \%$ at 1 year. The PC-ECMO risk score was developed using independent predictors of in-hospital mortality and showed better discrimination than the EuroSCORE II for this patient population. Further analysis demonstrated that greater-volume centers, with 50 or more cases of postcardiotomy VA-ECMO, had a 27\% lower relative risk of in-hospital mortality compared with lowervolume centers.

This is a large, robust analysis of patients with PCS requiring VA-ECMO support. The major lesson here is that despite improving perioperative care, patient outcomes remain poor in this population and have not improved compared with pooled historical data. ${ }^{6,7}$ A recently published analysis of the Extracorporeal Life Support Organization registry showed that survival to hospital discharge of patients requiring postcardiotomy VA-ECMO has decreased over the past 20 years. $^{8}$ At the heart of the

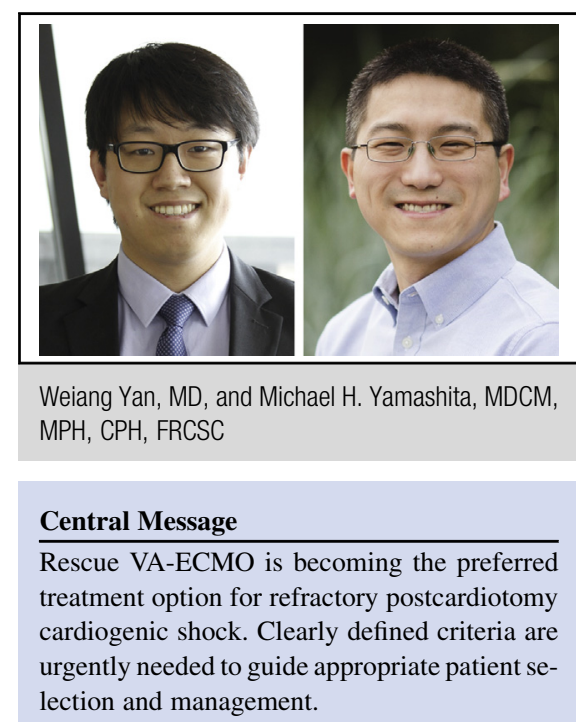

See Article page 1844.

problem is a lack of any uniform criteria for the institution, management, and weaning of postcardiotomy VA-ECMO. Appropriate patient selection has been shown repeatedly to be the most important predictor of outcomes in this patient population. In the present study, the authors attempt to address this problem through the PC-ECMO score. The risk factors identified are similar to those reported previously in other studies, including advanced age, high preECMO lactate, and greater case complexity.,10 The score still needs to be externally validated before widespread clinical use; however, it is a good initial step toward uncovering the key to better patient outcomes in this challenging population.

A limitation of this study is the lack of data on the overall incidence of PCS and outcomes with or without VA-ECMO. This information would shed light on the reasons behind the center volume-outcome relationship demonstrated in this study. Is this relationship due to increased experience leading to better results or lower-volume centers being extremely selective and using VA-ECMO for only salvage cases where the prognosis is extremely poor? Of note, the results of this study contradict previous findings that ECMO outcomes are not directly related to the total number of cases performed. ${ }^{11,12}$ In addition, this study failed to 
report on the effect of iatrogenic, intraoperative complications on the outcomes of ECMO. Issues such as surgical misadventure or suboptimal myocardial protection can be significant drivers of mortality, and ECMO therapy often cannot salvage the situation. Future collection of this information will be critical in helping surgeons choose the most appropriate patients for rescue VA-ECMO therapy.

\section{References}

1. Hernandez AF, Grab JD, Gammie JS, O’Brien SM, Hammill BG, Rogers JG, et al. A decade of short-term outcomes in post-cardiac surgery ventricular assist device implantation: data from the Society of Thoracic Surgeons' National Cardiac Database. Circulation. 2007;116:606-12.

2. Sanaiha Y, Bailey K, Downey P, Seo Y-J, Aguayo E, Dobaria V, et al. Trends in mortality and resource utilization for extracorporeal membrane oxygenation in the United States: 2008-2014. Surgery. 2019;165:381-8.

3. Sajjad M, Osman A, Mohsen S, Alanazi M, Ugurlucan M, Canver C. Extracorporeal membrane oxygenation in adults: experience from the Middle East. Asian Cardiovasc Thorac Ann. 2013;21:521-7.

4. Yang F, Jia Z, Xing J, Wang Z, Liu Y, Hao X, et al. Effects of intra-aortic balloon pump on cerebral blood flow during peripheral venoarterial extracorporeal membrane oxygenation support. J Transl Med. 2014;12:106.
5. Biancari F, Dalén M, Fiore A, Ruggieri VG, Saeef D, Jónsson K, et al. Multicenter study on postcardiotomy venoarterial extracorporeal membrane oxygenation. J Thorac Cardiovasc Surg. 2020;159:1844-54.e6.

6. Khorsandi M, Dougherty S, Bouamra O, Pai V, Curry P, Tsui S, et al. Extracorporeal membrane oxygenation for refractory cardiogenic shock after adult cardiac surgery: a systematic review and meta-analysis. J Cardiothorac Surg. 2017;12:55.

7. Biancari F, Perrotti A, Dalén M, Guerrieri M, Fiore A, Reichart D, et al. Metaanalysis of the outcome after postcardiotomy venoarterial extracorporeal membrane oxygenation in adult patients. J Cardiothorac Vasc Anesth. 2018;32: $1175-82$.

8. Whitman GJR. Extracorporeal membrane oxygenation for the treatment of postcardiotomy shock. J Thorac Cardiovasc Surg. 2017;153:95-101.

9. Rastan AJ, Dege A, Mohr M, Doll N, Falk V, Walther T, et al. Early and late outcomes of 517 consecutive adult patients treated with extracorporeal membrane oxygenation for refractory postcardiotomy cardiogenic shock. J Thorac Cardiovasc Surg. 2010;139:302-11.

10. Elsharkawy HA, Li L, Ali Sakr Esa W, Sessler DI, Bashour CA. Outcome in patients who require venoarterial extracorporeal membrane oxygenation support after cardiac surgery. J Cardiothorac Vasc Anesth. 2010;24:946-51.

11. McCarthy FH, McDermott KM, Spragan D, Hoedt A, Kini V, Atluri P, et al. Unconventional volume-outcome associations in adult extracorporeal membrane oxygenation in the United States. Ann Thorac Surg. 2016;102:489-95.

12. Bailey KL, Downey P, Sanaiha Y, Aguayo E, Seo YJ, Shemin RJ, et al. National trends in volume-outcome relationships for extracorporeal membrane oxygenation. J Surg Res. 2018;231:421-7. 